\title{
As Representações de Stephen Hawking em Filmes Biográficos
}

\section{The Representations of Stephen Hawking in the Biographical Movies}

\author{
(1) João Fernandes, (1) Guilherme da Silva Lima, (1) Orlando Aguiar Jr.
}

Palavras-chave Resumo Este artigo tem como objetivo analisar dois filmes biográficos Stephen Hawking; de Stephen Hawking com o intuito de identificar as representações do Representação do cientista presentes em obras cinematográficas. Para isso, a investigação cientista; contou com a análise fílmica e os filmes foram categorizados seguindo Cinema; as principais representações identificadas pela literatura. A análise Cultura científica. identificou as representações mais comuns presentes nas cenas e sequências em que o protagonista atuou, levando em consideração o contexto de determinadas ações do cientista. A representação de gênio foi a mais evidente nos dois filmes. Os resultados indicaram que as obras analisadas, de gênero biográfico, também estão fadadas a permear estereótipos que contribuem com uma visão deturpada do cientista e do labor científico, assim como acontece em outros gêneros cinematográficos.

Keywords Abstract This article aims to analyze two biographical films of Stephen Hawking; Stephen Hawking in order to identify the representations of the Representation of scientist present in cinematographic works. For this, the investigation scientist; was based on film analysis and categorization following the main Movies; representations identified in the literature. The analysis identified the Scientific culture. most common representations present in the scenes and sequences in which the protagonist acted, taking into account the context for certain actions of the scientist. The results indicated that the analyzed works, which belong to a biographical genre, are also bound to permeate stereotypes that contribute to a distorted view of the scientist and scientific work, just as it happens in other cinematic genres. 


\section{Introdução}

A ciência possui diversas interfaces com outras esferas da cultura humana, sendo possível encontrar obras literárias, plásticas, cênicas e cinematográficas que fazem referência ao universo científico. Tais referências não se pautam exclusivamente em questões específicas da cultura científica e tecnológica (CCT); muito pelo contrário, elas são capazes de se apropriar de temas, processos, linguagens, história, dentre outros elementos científicos e tecnológicos. Este trabalho considera como elementos da cultura científica todas as produções humanas que estabelecem diálogos com atividades, processos, conceitos, história e quaisquer outros aspectos da atividade científica e tecnológica, mesmo quando produzido em territórios fronteiriços, como a ficção científica.

As interfaces entre a CCT e a arte ocorrem por diversas razões, dentre as quais destacamos tanto o interesse da sociedade em temas científicos quanto a apropriação de temas de ciência e tecnologia pela indústria cultural. Atualmente, podemos acompanhar diversas temáticas científicas e tecnológicas que despertaram e despertam grande interesse da sociedade, tais como: mutação genética, viagens interplanetárias, inteligência artificial, aquecimento global etc.

As relações entre a produção artística e a CCT já foram discutidas por diversos pesquisadores (Cunha \& Giordan, 2009; Ferreira \& Raboni, 2013; Ramos \& Piassi, 2017; Zanetic, 2006) seja para indicar fronteiras e interações entre essas atividades, seja para indicar possibilidades de utilizar tais relações para a promoção da educação científica.

Um exemplo muito relevante da interação entre a ciência e a arte é a produção do filme Le voyage dans la Lune (Viagem a lua), dirigido por Georges Méliès e lançado em 1902, que estabelecia diálogos entre a obra cinematográfica, o conhecimento científico e as obras literárias Da terra à Lua e Os primeiros homens na lua, escritas pouco tempo antes por Júlio Verne e Herbert Wells, respectivamente (Roberts, 2016).

O cinema desde o início mantém muitas relações com a CCT, visto que, além de abordar suas temáticas e práticas, depende do desenvolvimento de novas ferramentas e técnicas para a produção de filmes. A sétima arte (como também é conhecido o cinema) se consolidou como uma forma de entretenimento com características próprias, sendo a apresentação de imagens em movimento a característica mais marcante. O cinema se apropriou de práticas sociais e "assimilou rapidamente elementos provenientes de todo o saber humano. A grandeza do cinema consiste em ele ser uma soma, assim como uma síntese de várias outras artes" (Sadoul, 1963, p. 7), promovendo assim alterações nas formas com as quais a realidade e a ficção são representadas artisticamente.

A indústria cultural tem se apropriado do imaginário científico para produzir filmes, livros, imagens etc. Com isso, ela também promove atividades que contribuem para a produção desse imaginário. Assim, a CCT não é exclusivamente uma fonte possível, mas também é retroalimentada pelos produtos da indústria cultural e, em especial, pelas produções cinematográficas.

Nesse sentido, a CCT pode ser compreendida como um produto gerado a partir 
de diversas fontes. Assim as percepções e concepções que os indivíduos criam sobre a ciência e tecnologia estão fundamentadas em diversos suportes midiáticos (programas televisivos e radiofônicos, filmes, artigos e entrevistas em jornais e revistas etc.), além das conversas com amigos e familiares e da escola, concepção que é classificada como modelo de rede no campo da comunicação pública da ciência (Polino \& Castelfranchi, 2012). O cinema, por sua vez, se configura como um suporte capaz de fomentar a percepção e o imaginário de elementos da CCT.

Entender a CCT por meio do modelo de rede significa desconstruir a ideia de que existe um centro produtor dessa cultura e considerar as trocas sociais como partes integrantes da produção da CCT e, em consequência, do imaginário científico. Quando relacionamos o modelo de rede com a produção cinematográfica, podemos destacar a influência que o cinema tem para a manutenção da cultura e do próprio imaginário por meio da representação de atividades científicas e seus agentes.

Tendo em vista que o imaginário científico é determinado coletivamente, as obras cinematográficas tanto produzem quanto reproduzem características que compõem esse imaginário. Nesse sentido, a análise de obras cinematográficas pode nos indicar aspectos relevantes da relação entre o cinema e o imaginário científico.

Este artigo tem como objetivo analisar dois filmes biográficos de Stephen Hawking visando evidenciar as formas e os contextos em que as representações do cientista são apresentadas pelas obras "A História de Stephen Hawking" e "A Teoria de Tudo". Visando o delineamento de orientações claras para a investigação, propusemos os seguintes questionamentos: como e em quais contextos são apresentadas as representações atribuídas a Stephen Hawking?

Para responder a essa indagação recorremos a uma pesquisa com abordagem qualitativa, de estudo de caso. Os filmes foram analisados por meio de uma combinação de técnicas que contemplam considerações acerca da natureza do cinema, a análise de conteúdo para filmes (Penafria, 2009) e a triangulação histórica.

É importante ressaltar a relevância de analisar obras cinematográficas biográficas, uma vez que os campos de investigação (educação em ciências, estudos culturais e divulgação científica) que voltam esforços para compreender os diálogos entre o cinema e a ciência geralmente não focam esse gênero cinematográfico. A ficção científica e o documentário são os principais filmes investigados. Nesse sentido, o estudo das biografias pode ampliar a compreensão da área no que se refere às interfaces entre o cinema e a ciência. Vale lembrar que a obra biográfica no cinema não deve ser interpretada como uma representação fidedigna da história do personagem, mas como uma representação, que além da história, contém elementos artísticos e efeitos para promover o entretenimento. Assim, o estudo dessas obras também pode indicar formas críticas para o seu uso em contextos educativos.

A escolha de se fazer um trabalho centrado na representação de Stephen Hawking é fundamentada na relevância que o físico e cosmólogo teve e ainda tem, tanto na produção científica quanto na divulgação científica. Por meio de suas teorias e 
livros, Stephen Hawking ficou mundialmente conhecido ao formular uma teoria sobre o início do universo que corrobora a Teoria do Big Bang. Hawking afirmou em sua tese de doutorado, em 1966, que no início toda matéria estava condensada em uma singularidade, assim como os buracos negros (Hawking, 1993). Posteriormente, em 1974, Hawking trouxe outra contribuição ao entendimento sobre os buracos negros ao teorizar que nem tudo fica neles confinado e que uma radiação é expelida de seus núcleos (Hawking, 1975). Essas são apenas algumas das contribuições de Hawking para a ciência e não cabe aqui listar todas.

Outro ponto que contribuiu com a fama internacional de Hawking foi a publicação de vários livros de divulgação científica. "Uma breve história do tempo", de 1988, se tornou o maior best seller da categoria, tendo vendido mais de 25 milhões de cópias até 2007 (McKie, 2007). Sua iniciativa de criar instrumentos que pudessem levar a ciência para além da academia, também motivou pesquisadores da área a olharem para suas obras. Em suma, Hawking foi capaz de quebrar as barreiras entre a cultura científica e a sociedade, além de motivar pesquisadores de diversas áreas do conhecimento (Grego, 2013).

Destacamos, ainda, a importância da discussão acerca das interfaces entre a cultura científica e a arte, no campo da educação em ciências, pois a formação científica dos sujeitos e da sociedade não ocorre exclusivamente pela educação formal. A educação informal é um processo determinante na educação científica e por vezes é negligenciada. O consumo do cinema, e de outras produções artísticas e comunicacionais, pode contribuir com a formação científica na medida em que aborda temáticas científicas, enquanto dissemina valores e ideias. De acordo com Smith (2001, tradução livre), a educação informal é compreendida como um

processo verdadeiramente ao longo da vida em que cada indivíduo adquire atitudes, valores, habilidades e conhecimentos a partir da experiência diária e das influências e recursos educacionais em seu ambiente - da família e vizinhos, do trabalho e do lazer, do mercado, da biblioteca e os meios de comunicação de massa. ${ }^{1}$

Além de seu papel da educação informal, os filmes têm grande potencial para enriquecer o conjunto de recursos utilizados por professores no ensino de ciências. No caso das obras escolhidas para análise, os filmes biográficos sobre Stephen Hawking podem contribuir para a inserção de temas de física moderna, especialmente a cosmologia, em situações educativas. Diversos pesquisadores do campo da educação em ciências indicam as potencialidades do cinema para a educação científica. Tais contribuições se concentram predominantemente no uso da ficção científica (Cunha \& Giordan, 2009; Piassi, 2013; Piassi \& Pietrocola, 2009; Santos \& Silva, 2017) e, em segundo plano, dos documentários (Barbosa \& Bazzo, 2013; Cazón \& Oliveira, 2018;

1 No original: The truly lifelong process whereby every individual acquires attitudes, values, skills and knowledge from daily experience and the educative influences and resources in his or her environment - from family and neighbours, from work and play, from the marketplace, the library and the mass media. 
Marcelo \& Ripoll, 2016).

Dentre as contribuições para a educação científica ressaltamos a proposta de Piassi e Pietrocola (2009) que apresentam alternativas que vão além do uso tradicional do cinema em situações de ensino, que geralmente está concentrado em encontrar e explicar erros conceituais em filmes. Os autores propuseram um método de análise de conteúdo de filmes de ficção científica que, analisando elementos contrafactuais presentes, podem ter usos distintos no ensino de ciências. Alcântara e Lima (2018), por sua vez, utilizaram da metodologia de um cinedebate para aproximar a comunidade da CCT. Os autores identificaram categorias de elementos científicos e tecnológicos presentes nas obras cinematográficas que podem ser utilizadas para a seleção e análise de filmes em situações de educação científica.

A importância do uso do cinema em situações de ensino não está relacionada exclusivamente ao desenvolvimento dos conteúdos escolares. Cunha e Giordan (2009) ressaltam que "Um filme na sala de aula deve servir como objeto de estudo, pois a escola precisa mediar criticamente os aspectos da cultura cotidiana no contexto escolar, no sentido de intervir positivamente na interpretação dos meios de comunicação"(pp. 1516). Tal consideração se torna mais pertinente na medida em que compreendemos que o diálogo entre uma obra cinematográfica e a CCT indica a "ciência como cultura inserida no contexto sociocultural de uma sociedade” (Piassi, 2013, p. 531).

Acreditamos, portanto, que os dois filmes que retratam a biografia de Stephen Hawking podem ser utilizados de diversas maneiras na educação formal e/ou informal em ciências, das quais destacamos: a) introdução à cosmologia; b) discussão sobre o labor científico; c) problematização da imagem do cientista representada nos filmes.

\section{As imagens dos(as) cientistas no cinema}

As representações dos(as) cientistas estão presentes em diversas outras atividades artísticas e comunicativas e contribuem tanto quanto o cinema para a produção da imagem do(a) cientista na sociedade, sendo, inclusive, objeto de diversas pesquisas, a exemplo de Almeida e Lima (2016), Gorp et al. (2013), Long et al. (2014), Marcelo e Ripoll (2016), Reznik e Massarani (2019), e Scalfi e Oliveira (2015). Essas imagens e representações, em última instância, podem contribuir para produzir perfis de percepção da ciência e tecnologia, bem como para a consolidação da memória coletiva, fazendo com que determinadas interpretações da realidade sejam apropriadas massivamente pelas pessoas.

De acordo com Perez (2012), as imagens e representações que um grupo da sociedade faz, a fim de categorizar padrões de um objeto, pessoa, profissão etc., é chamado estereótipo. Para a autora "o estereótipo é uma forma de simplificar nossa visão de mundo, poupando tempo e energia ao realizar determinadas generalizações" (p. 885). Embora a definição de estereótipo tenha nuances diferentes para cada autor, o que se assemelha entre elas é que é uma "crença compartilhada acerca de atributos traços de personalidade ou comportamentos - de grupos de pessoas" (Rodrigues et al., 1999, p. 150) 
Weingart et al. (2003) contribuem para a investigação sobre a representação dos(as) cientistas em filmes. Ao analisar 222 filmes hollywoodianos de ficção científica, os autores destacam que os cientistas são caucasianos (96\%), do sexo masculino (82\%) e americanos (49\%). Eles alegam ainda que as aparências dos(as) cientistas são discretas e caricaturadas. Tais resultados, consolidam as representações de cientistas como carreiras masculinas marcadas pela excentricidade da aparência. Resultados semelhantes foram também encontrados por Ramos e Olschowsky (2009) em filmes de animação.

A predominância masculina não exclui a representação de cientistas mulheres. Jackson (2011) investigou a representação da mulher cientista em filmes de terror alternativos. Ao analisar 17 filmes, a autora destaca que a representação da cientista como louca é retratada em quatro filmes além de dois outros que dão indícios de que posteriormente a cientista poderá desenvolver a loucura... Tal resultado, apesar de se enquadrar em uma representação comum do cientista, não é usual para a representação da cientista mulher, como é apontado por Flicker (2003):

A descrição clichê de cientista louco não é aplicada às cientistas mulheres. Elas não trabalham em laboratórios escondidos em projetos duvidosos, mas permanecem sólidas, 'com os pés no chão'. Personagens femininas nos filmes não contribuem para construir mitos negativos acerca da imagem da ciência (p. 316, tradução livre) $)^{2}$.

Flicker (2003) destaca ainda que nas personagens que retratam cientistas mulheres o estereótipo profissional é sobreposto por um estereótipo de gênero. Por isso, as cientistas nos filmes não representam a racionalidade científica frequentemente representada por figuras de cientistas homens. Ao invés disso, as mulheres cientistas resgatam a intuição, a emoção e os sentimentos.

Weingart et al. (2003) tentam ir além da recorrente representação do(a) cientista como louco, ainda que esta essa seja predominante. Uma das outras representações identificada pelos autores é a do(a) cientista benevolente, o que não implica na ausência de contradições e ambivalências. De acordo com os pesquisadores, nesse tipo de representação os(as) cientistas podem ser caracterizados como facilmente manipulados; idealistas que se corrompem; ambiciosos e dispostos a violar princípios éticos em prol do conhecimento ou da carreira. Tais resultados indicam antagonismos nas representações do(a) cientista, resultado que é compatível com as considerações de Oliveira (2006), que destaca que

as imagens e representações da ciência e seus representantes nos filmes são flutuantes e podem ser discrepantes. Cientistas são, por exemplo, estereotipados simultaneamente como astuciosos e ingênuos, humildes e prepotentes. Na análise do imaginário científico, entretanto, a coexistência de representações opostas não significa necessariamente dissonância (Oliveira, 2006, p. 148).

2 No original: The cliché description of "mad scientist" does not apply to women scientists. They do not work in hidden laboratories on dubious projects but rather, remain solid 'with their feet on the ground.' Female characters in feature films do not contribute to the build up of negative myths surrounding the image of science. 
Para além da ficção científica, os documentários (outro gênero do cinema) também produzem representações de cientistas. Gingras (2007) analisa o documentário sobre Poincaré La relativité, Poincaré et Einstein, Planck, Hilbert: Histoire véridique de la théorie de la relativité (Relatividade, Poincaré e Einstein, Planck, Hilbert: História verdadeira da teoria da relatividade), lançado em 2004, que problematiza a apropriação das contribuições de Poincaré por Einstein para a produção da teoria da relatividade restrita. Em seus resultados, o autor destaca a representação de Poincaré feita pelo filme: um cientista solitário, desorganizado e genial ${ }^{3}$, que contribuiu para diversos campos do saber, características essas que se enquadram nas representações mais comuns na constituição da imagem do(a) cientista.

As representações de cientistas no cinema, por vezes, desconsideram os contextos sociais e culturais que permeiam as atividades dos(as) cientistas, de modo que tanto os filmes de ficção científica quanto os documentários pouco retratam os aspectos privados da vida desses(as) personagens (Gingras, 2007; Weingart et al., 2003). Poincaré, por exemplo, "é apresentado como uma mente pura flutuando no mundo dos números platônicos, enquanto a tecnologia e a sociedade passam como um mero pano de fundo" 4 (Gingras, 2007, p. 371). Tais características são justificadas pelas agendas próprias dos produtores cinematográficos (Gingras, 2007), as quais podem estar baseadas nas coerções da indústria cultural, que, por vezes, enfatizam a dramatização e a captação do público. Tais considerações podem ser ampliadas, sem acarretar muitos problemas, para os filmes de ficção científica.

Essas contribuições esboçam as principais representações de cientistas presentes em filmes ao longo da história, com destaque para a de cientista louco, ao mesmo tempo em que o gênero que mais aborda temas científicos é o Terror (Weingart et al., 2003).

Considerando as transformações sociais que têm ocorrido nas últimas décadas, não podemos negligenciar as críticas de Haynes (2016), que alega que "desde 2001, nós temos aprendido a temer mais o terrorismo e o fanatismo provenientes de sistemas políticos e fundamentalismos, baseados na loucura imprevisível de líderes despóticos ou fanáticos" ${ }^{\prime 5}$ (p. 42). Com isso, parte dos medos provenientes da modernidade e do pós-guerra, que predominantemente estavam associados ao desenvolvimento científico e tecnológico, fica em segundo plano.

Haynes (2016) defende que a representação de cientistas tem sido revisada desde o início do século 21. Barca (2005) constatou que houve uma mudança significativa: nos anos 1960, o(a) cientista era figura central de longas-metragens, atuando, especialmente, como o vilão; em meados dos anos 1980, essa figura passou a ter um papel secundário, porém o desenvolvimento da narrativa era baseado nos feitos de grupos de pesquisadores;

3 Todas as menções ao termo gênio são utilizadas para fazer referência a personagens da história que não necessitam desempenhar grandes esforços para atingir os seus feitos intelectuais.

4 No original: Poincaré is presented as a pure mind floating in the world of Platonic numbers, while technology and society pass by as a mere backdrop

5 No original: Since 2001, we have learned to fear most the terrorism and fanaticism arising from political systems and fundamentalism and, underpinning them, the unpredictable madness of despotic or fanatical leaders. 
no início dos anos 2000, o(a) cientista retomou o seu papel como protagonista, dessa vez como herói, exaltando suas características físicas e manuais, como se todo o conhecimento científico fosse apenas um complemento aos seus atributos naturais. Tais resultados indicam a relevância de trabalhos como este, pois contribui para compreender essa nova representação.

O trabalho de Barca mostra como a imagem do(a) cientista no cinema pode variar historicamente. Nesse sentido, entendemos que a imagem do cientista pode alterar de acordo com as transformações sociais, que podem determinar novos caminhos para representá-lo. Cabe ressaltar, contudo, a predominância e a manutenção de determinados estereótipos que se fundamentam em preconceitos de gênero e étnicos, tendo como principal referência o fato de que, majoritariamente, os cientistas são representados como homens brancos (Flicker, 2003; Weingart et al., 2003).

Considerando tanto as transformações na representação do cientista no século 21 quanto as diversas transformações sociais que questionam as imagens e os papéis sociais de seres humanos, queremos entender as representações de um cientista mundialmente reconhecido em filmes biográficos.

\section{Como analisar Hawking e as teorias de tudo?}

É importante ressaltar que as representações de cientistas indicadas na literatura estão baseadas, predominantemente, na ficção científica. Reconheçamos as diferenças entre o gênero cinematográfico ficção científica e a biografia (objeto de análise deste artigo), mas vale ressaltar dois pontos: após a década de 1970 a hibridização de gêneros cinematográficos passa a ser recorrente nos filmes (Johnston, 2011), inclusive as duas obras analisadas reconhecem a existência de cenas ficcionais; 2. São escassas as investigações que analisam obras biográficas do cinema e suas relações com a cultura científica, sendo mais comuns trabalhos que investigam a ficção científica. Ainda com essas considerações, a aproximação das representações do cientista na ficção científica e na biografia nos conduz ao seguinte problema: seriam as categorias propostas para analisar filmes de ficção científica também adequadas para análise de filmes biográficos? Para responder a esta questão, devemos examinar a natureza dos personagens em obras de ficção científica e de biografias.

O primeiro ponto a ser destacado é a natureza da personagem de ficção. Candido (1968) destaca:

A personagem é um ser fictício, - expressão que soa como paradoxo. De fato, como pode uma ficção ser? Como pode existir o que não existe? No entanto, a produção literária repousa nesse paradoxo, e o problema da verossimilhança no romance depende dessa possibilidade de um ser fictício, isto é, algo que, sendo uma criação da fantasia, comunica a impressão da mais lídima verdade existencial. Podemos dizer, portanto, que o romance se baseia, antes de mais nada, num certo tipo de relação entre o ser vivo e o ser fictício, manifestada através da personagem, que é a concretização deste (p. 32). 
Isso significa que a personagem de ficção não é uma produção imaginária fundamentalmente separada da realidade. Candido (1968) esclarece que "a personagem deve dar a impressão de que vive, de que é como um ser vivo. Para tanto, deve lembrar um ser vivo, isto é, manter certas relações com a realidade do mundo" (p. 39). O autor apresenta um panorama das personagens já produzidas na literatura e ressalta que "houve na evolução técnica do romance um esforço para compor seres íntegros e coerentes, por meio de fragmentos de percepção e de conhecimento que servem de base à nossa interpretação das pessoas" (Candido, 1968, p. 36). Assim, a personagem na ficção é uma produção que congrega características do real e, portanto, suas características e sua personalidade podem ser interpretadas como sínteses de características humanas.

Por outro lado, a personagem da biografia não deve ser interpretada como uma imagem fidedigna da realidade, isto é, a personagem não deve ser vista como um espelho da pessoa representada. Sob a perspectiva da historiografia, Schmidt (2014) apresenta considerações importantes sobre a biografia, defendendo ser necessário considerar que

a biografia é sempre uma construção possível, entre tantas outras, a respeito de um personagem, e nunca "o" retrato definitivo. Neste sentido, precisa renunciar à busca de uma essência social ou psicológica que explique a trajetória examinada, para levar em conta as mudanças de rota, os percalços, os acasos, os possíveis de cada existência (p. 199).

Nesse sentido a biografia não deve ser vista e analisada como a história fidedigna da personagem, mas como um gênero híbrido entre o real e a ficção. Por isso, ao mesmo tempo em que é capaz de sintetizar momentos importantes da história e das experiências da personagem, também recria e adiciona elementos ficcionais para a composição da obra. Assim, em uma obra biográfica, a personagem não é a representação de uma pessoa em sua integridade.

Candido (1968) contribui com essa discussão ao ressaltar a impossibilidade de "transplantar" um personagem real para o romance:

Poderia então a personagem ser transplantada da realidade para que o autor atingisse este alvo? Por outras palavras, pode-se copiar no romance um ser vivo e, assim, aproveitar integralmente a sua realidade? Não em sentido absoluto. Primeiro, porque é impossível, como vimos, captar a totalidade do modo de ser duma pessoa, ou sequer conhecê-la; segundo, porque neste caso se dispensaria a criação artística; terceiro, porque, mesmo se fosse possível, uma cópia dessas não permitiria aquele conhecimento específico, diferente e mais completo, que é a razão de ser, a justificativa e o encanto da ficção (p. 39).

Por tudo que foi dito, entendemos que as personagens da ficção e da biografia possuem elementos do real e elementos do ficcional. Por isso, consideramos a pertinência e a coerência do uso de categorias propostas para analisar filmes de ficção científica para analisar filmes biográficos.

Esta investigação adotou uma abordagem qualitativa, cuja metodologia de 
pesquisa contou com uma combinação de técnicas, que contemplam considerações acerca da natureza do cinema, a análise de conteúdo para filmes (Penafria, 2009) e a triangulação histórica, restrita a momentos científicos relevantes da vida de Hawking.

O primeiro filme analisado neste trabalho foi "A história de Stephen Hawking" (Martin, 2004). Este longa foi produzido pela empresa inglesa BBC, com o intuito de encenar a passagem de Stephen Hawking pela Universidade de Cambridge. O filme foi baseado em relatos reais e documentados, embora, segundo os produtores, algumas cenas tenham sido inventadas para conseguir unir os eventos da história do cosmólogo.

O segundo filme, "A teoria de tudo" (Marsh, 2014), foi produzido pela Universal Studios. Com o intuito de retratar parte da vida de Hawking, o longa foi baseado no livro que sua primeira esposa, Jane, escreveu - Travelling to infinity: My life with Stephen. Embora tenha sido baseado neste livro, o filme foi produzido por uma empresa reconhecida por um tipo de modelo comercial de produção cinematográfica típico de Hollywood. Nesse sentido, consideramos desde o início da investigação que a obra poderia conter elementos incluídos devido às pressões da indústria cultural e desse modelo de produção.

Rose (2013), ao discutir sobre a metodologia de análise de imagens em movimento (filmes), destaca a necessidade de não se reduzir esse registro à proeminência do texto. A produção de audiovisuais inclui diversos elementos que produzem sentidos (como a iluminação, o enquadramento, a trilha sonora, a sequência, os elementos presentes na cena etc.), e por isso não podem ser desprezados. De acordo com Rose (2013),

os meios audiovisuais são um amálgama complexo de sentidos, imagens, técnicas, composição de cenas, sequências de cenas e muito mais. É, portanto, indispensável levar essa complexidade em consideração, quando se empreende uma análise de seu conteúdo e estrutura (p. 343).

Tais considerações destacam a complexidade da análise de filmes. Para este trabalho, não foi possível realizar uma análise que contemplasse toda a diversidade de elementos contidos nos filmes. Contudo, tentamos considerar elementos essenciais na produção de sentidos que estivessem relacionados à representação de cientistas, em especial: a cena, a sequência, a trilha sonora e o texto.

Penafria (2009) destaca que a análise de conteúdo quando aplicada à investigação de filmes consiste em distinguir seu tema central e a partir dele realizar decomposições tendo em conta o que o filme diz sobre o tema. Esse tema, normalmente, dialoga com questões que não estão explícitas no filme, e que podem ser trazidas para a realidade do analista.

A triangulação com a história do cientista foi realizada por meio dos livros Stephen Hawking, a life in science, escrito por Michael White e John Gribbin (2002), e Stephen Hawking, his life and work, escrito por Kitty Ferguson (2011) e revisado pelo próprio Hawking. Essa técnica foi utilizada com o intuito de fortalecer a interpretação de estereótipos presentes nos filmes. Salientamos, porém, que como os filmes foram criados com o propósito de entretenimento e arte (visto que esses são os principais propósitos do 
cinema), esses não têm a obrigatoriedade de representar fidedignamente os fatos. Além disso, as biografias também podem conter representações estereotipadas de Hawking, uma vez que retrata uma história possível (Schmidt, 2014). Nesse sentido, este trabalho não deve ser interpretado como pertencente ao campo da história e filosofia da ciência ${ }^{6}$.

As análises foram feitas a partir da separação de cenas e de sequências que evidenciaram representações de Hawking. De acordo com Suppia (2015), os conceitos de cena e de sequência se confundem por não existir definições claras e amplamente adotadas pela comunidade. Decidimos adotar a concepção de Vsevold Pudovkin de que o "roteiro de filmagem completo é dividido em sequências, cada sequência dividida em cenas e, finalmente, as cenas mesmas são construídas a partir de séries de planos, filmados de diversos ângulos" (1983, p. 57, citado em Suppia, 2015). Tendo como base essa definição, separamos cenas e sequências que evidenciaram direta ou indiretamente as representações relacionadas a Stephen Hawking. Apresentamos nas análises algumas transcrições de diálogos que sustentam determinada ação que pode ser classificada no escopo de alguma representação.

Conduzidos por essa orientação metodológica analisamos a dinâmica narrativa, os pontos de vista expressados no filme e as cenas e sequências selecionadas, de acordo com o seguinte percurso: análise e decomposição temática dos filmes; seleção das cenas e sequências que possuem indícios de representações do cientista; análise descritiva das cenas e sequências visando identificar as representações presentes. Portanto, as análises foram realizadas com base na representação do cientista em determinada cena ou sequência. Reconhecemos que essa escolha metodológica pode não ser capaz de contemplar aspectos relativos à personalidade do cientista, uma vez que determinado comportamento pode estar associado a situações vivenciadas por Hawking que o conduziram a tomar decisões que talvez ele não tomaria em outras condições. Assim, para tentar contemplar as nuances das escolhas do cientista, os filmes foram analisados novamente tentando captar a historicidade e o contexto encenado até a cena ou sequência selecionada. Destacamos situações que consideramos mais relevantes para a análise, como os motivos e os contextos que estavam envolvidos.

A análise foi realizada buscando identificar as representações mais recorrentes de acordo com a literatura (Flicker, 2003; Gingras, 2007; Jackson, 2011; Oliveira, 2006; Weingart et al., 2003), a saber: antissocial; atrapalhado; caucasiano; com aparência discreta e caricaturada; confuso (embora genial); desorganizado; excêntrico; genial; louco; homem; solitário; benevolente, porém com diversas ambivalências; facilmente manipulável; idealista que se corrompe; ambicioso; disposto a violar princípios éticos em prol do conhecimento científico; alienado do mundo real. Destacamos que as categorias encontradas na literatura serviram de plano inicial de análise, mas que a pesquisa buscou identificar outras representações, para além dessas.

6 Reconhecemos que o diálogo com a história e filosofia da ciência pode apresentar novas nuances e contribuir para a análise crítica das obras no cinema e possíveis usos na educação científica. Contudo, esse diálogo foge do escopo deste artigo. Indicamos essa possibilidade como alternativa para investigações futuras. 
Ressaltamos que a análise apresentada busca ir além da catalogação das representações presentes na obra. Entendemos que compreender os contextos e os motivos que levaram o personagem a tomar determinada decisão é mais importante do que saber qual o estereótipo representado. Essa interpretação está baseada no fato de que o espectador não absorve passivamente os sentidos e valores expressados no filme, mas, ao contrário, estabelece relações entre os fatos representados e busca interpretar as cenas, sentidos e valores presentes na obra. Ressaltamos que, embora a catalogação de estereótipos tenha sido relevante para compreender as formas de representação do cientista, tomamos o cuidado de não fazer interpretações isoladas, de forma a evitar análises equivocadas e deturpadas dos sujeitos que atuam na cultura científica. Assim, defendemos a necessidade de avançar no sentido de compreender os contextos e motivos que guiam as ações do personagem, pois esses, mais do que a categoria de estereótipo, podem ser interpretados e reproduzidos pelos espectadores. Compreender os contextos e motivos das ações do personagem pode nos indicar mais elementos para entender os motivos de interpretações estereotipadas dos cientistas pelos espectadores, uma vez que permitem a produção de uma representação justificada racionalmente.

\section{A história de Stephen Hawking}

O filme "A história de Stephen Hawking" retrata a passagem do físico pela Universidade de Cambridge, Inglaterra, durante o processo de produção e defesa da sua tese de doutorado. Segundo a produtora, BBC, a obra cinematográfica foi baseada em vídeos e textos da época, embora ressalte que algumas cenas foram inventadas para poder suprir lacunas entre os eventos.

A obra conta com três fios narrativos que se desenvolvem paralelamente. $\mathrm{O}$ primeiro e principal representa a vida científica de Stephen, focando especialmente em suas contribuições durante a realização do doutorado, com enfoque especial no embate entre a Teoria do Estado Estacionário e a Teoria do Big Bang, que Stephen corroborou suas elaborações teóricas. A segunda narrativa aborda o desenvolvimento da doença de Hawking. Essa abordagem não ocupa muito tempo da obra, mas apresenta momentos determinantes da vida do cientista. A terceira narrativa, por sua vez, apresenta uma entrevista com Arno Penzias e Robert Woodrow Wilson, que em 1965 detectaram a radiação de fundo, que foi fundamental para a consolidação da Teoria do Big Bang. As relações sociais com a família, os amigos e com Jane, sua futura esposa, que não estabeleciam relações com o desenvolvimento da carreira ou com o tema ciência, são raras no filme, o que nos levou a considerar que não existe um quarto fio narrativo. Como o objetivo do trabalho é investigar a representação do cientista, os trechos analisados a seguir são extraídos predominantemente da narrativa do desenvolvimento da carreira de Hawking.

A seguir dispomos uma figura contendo todas as cenas/sequências analisadas, $o$ tempo em que elas são apresentadas e uma breve descrição das mesmas (Figura 1). 
Figura 1. Cenas e sequências do filme "A história de Stephen Hawking"

\begin{tabular}{|c|c|c|}
\hline Cena/ Sequência & Tempo & Descrição \\
\hline 1 & $\begin{array}{l}2: 30- \\
8: 13\end{array}$ & $\begin{array}{l}\text { Festa de aniversário de Stephen. O físico num primeiro momento é } \\
\text { retratado isolado na sala de estar, e em seguida conversando com Jane, } \\
\text { sua futura esposa. }\end{array}$ \\
\hline 2 & $\begin{array}{l}8: 13- \\
10: 28\end{array}$ & $\begin{array}{l}\text { Consulta médica. Stephen após tropeçar e não conseguir se levantar, } \\
\text { durante a sua festa de aniversário, é levado ao médico. }\end{array}$ \\
\hline 3 & $\begin{array}{l}27: 47- \\
31: 33\end{array}$ & $\begin{array}{l}\text { Encontro com amigos no bar. Hawking é desafiado por um de seus } \\
\text { amigos a flertar com uma garota utilizando somente a Teoria da } \\
\text { Relatividade. }\end{array}$ \\
\hline 4 & $\begin{array}{l}36: 32- \\
39: 11\end{array}$ & $\begin{array}{l}\text { Debate com Hoyle nos corredores. Após a entrevista Stephen e Hoyle } \\
\text { discutiram sobre a Teoria do Estado Estacionário. }\end{array}$ \\
\hline 5 & $\begin{array}{l}40: 15- \\
43: 23\end{array}$ & $\begin{array}{l}\text { Almoço com Stephen, Penrose, Sciama e sua esposa. Nesse almoço, os } \\
\text { quatro conversam sobre o tempo e suas diversas interpretações. }\end{array}$ \\
\hline 6 & $\begin{array}{l}43: 38- \\
47: 15\end{array}$ & $\begin{array}{l}\text { Investigação do trabalho de Hoyle. Stephen analisa os cálculos } \\
\text { matemáticos do trabalho de Hoyle a fim de encontrar equívocos. }\end{array}$ \\
\hline 7 & $\begin{array}{l}47: 15- \\
51: 21\end{array}$ & $\begin{array}{l}\text { Contestação do trabalho de Hoyle. Hawking faz uma crítica } \\
\text { contundente ao trabalho de Hoyle em meio a uma apresentação do } \\
\text { cosmólogo na Royal Society. }\end{array}$ \\
\hline 8 & $\begin{array}{l}63: 13- \\
64: 49\end{array}$ & $\begin{array}{l}\text { Confraternização num bar de Jazz. Stephen, Jane e um amigo deles } \\
\text { (não foi citado seu nome) confraternizam num bar de Jazz. }\end{array}$ \\
\hline 9 & $\begin{array}{l}68: 52- \\
72: 30\end{array}$ & $\begin{array}{l}\text { Insight na estação Cambridge. Durante o retorno à Universidade, } \\
\text { Stephen tem um insight sobre a sua pesquisa, enquanto está sentado } \\
\text { no trem. }\end{array}$ \\
\hline
\end{tabular}

A representação de Stephen teve início em sua festa de aniversário, na qual sua futura primeira esposa, Jane Wilde, estava presente. Podemos perceber que o físico estava inserido num evento bem diferente das representações clássicas de cientistas, que destacam esses sujeitos como antissociais e introvertidos. Apesar do contexto, são notórios os elementos referentes ao isolamento social de Hawking, uma vez que na primeira cena dessa sequência ele estava sozinho em uma sala assistindo ao professor Hoyle, cosmólogo defensor da Teoria do Estado Estacionário, na televisão falando sobre assuntos científicos, no caso relacionado à sua futura tese. Outro elemento evidente é a ação da mãe do cientista, Isobel, que procurou orientar o comportamento dele durante a festa, ação que é manifestada na fala da personagem: "[Isobel] Stephen! Isso é uma festa. As pessoas podem querem dançar, não dá para dançar Wagner". Além disso, é evidente nessa sequência que Hawking interagiu exclusivamente com três pessoas: Isobel, Jane e Frank Hawking, seu pai. Portanto, esses elementos evidenciam representações relacionadas ao isolamento social e ao comportamento inadequado (talvez extravagância ou excentricidade).

Outro ponto a se destacar, na primeira sequência, é que Stephen foi apresentado como representante e mantenedor do discurso científico, pois o principal diálogo 
estabelecido versava sobre o universo e a revolução galileana (história da ciência). No final do mesmo diálogo houve uma mudança do objeto discursivo que passou a ser a música, momento em que o cientista demonstrou senso de humor e descontração.

Na sequência seguinte (2), o cientista também foi representado como mantenedor do discurso científico. Durante sua primeira ida ao médico, devido aos primeiros indícios de sua doença, o diretor do filme tem a intenção de passar a imagem de que o personagem via conceitos científicos em qualquer diálogo, mesmo nos mais triviais e cotidianos. Essa ideia pode levar à interpretação de que Hawking fosse incapaz de manter um diálogo longo que não retornasse à ciência e à sua futura tese de doutorado.

A representação de Stephen como antissocial e introvertido foi reforçada até os 28 minutos do filme, pois não foram mencionados os seus amigos, o que parece enfatizar a ideia de que cientistas são solitários. Na sequência (3) em que seus amigos apareceram, eles lhes fizeram um desafio: o protagonista deveria conquistar uma garota utilizando somente a teoria da relatividade de Einstein, o que reforça a ideia de que cientistas só conseguem falar sobre ciência e são incapazes de conversar sobre assuntos gerais. Por fim, nessa sequência de quatro minutos, Stephen conseguiu identificar um apontamento para o tema do seu doutorado durante o flerte a que foi desafiado.

Essa cena, quando analisada isoladamente, indica uma representação de que cientistas só conseguem se comunicar por intermédio da ciência. Porém, quando consideramos o contexto social no qual o personagem está inserido, a interpretação pode ser diferente. O cosmólogo foi desafiado por um colega físico teórico, cujo nome não foi revelado, a conquistar uma garota utilizando a teoria da relatividade. Desta forma, não podemos afirmar que o cientista falasse apenas sobre ciência, posto que fora submetido a essa situação. Outro motivo que pode ter levado o cosmólogo a aceitar a aposta está relacionado às provocações que o colega fez, antes do desafio, em relação às descobertas da cosmologia, alegando que essas não serviam para o "mundo real".

Aos 36 minutos (sequência 4), durante uma gravação, possivelmente uma entrevista ou um material para divulgação científica com Fred Hoyle, Stephen e Dennis Sciama, seu orientador, estavam assistindo e discutindo possíveis temas para a sua pesquisa e falavam sobre a Teoria do Estado Estacionário, tema abordado por Hoyle. No decorrer da conversa, Stephen fez um questionamento acerca dessa teoria, considerando que ela eliminava a possibilidade do início do Universo, e indicou que a Teoria do Big Bang poderia ser coerente. Ao escutar isso, Hoyle, que já havia terminado a gravação e passava pelo corredor ao lado de Sciama e Hawking, criticou intensamente a Teoria do Big Bang. Com uma narrativa sarcástica e arrogante, ele ridicularizou o cosmólogo alegando que a Teoria do Big Bang seria algo dos desenhos animados: "[Hoyle] A essência da Teoria do Big Bang é que ela é errada. Irracional e errada. É meu termo, 'Big Bang'. Fui eu que inventei. Sabe por que eu chamei assim? Porque soa como algo vindo de um desenho animado. Big Bang é a física dos desenhos animados". Em seguida, Hoyle alegou sarcasticamente que o modelo do Big Bang corrobora a existência de Deus. Durante a sequência, Stephen escutou atentamente o cientista enquanto o seguia pelo corredor, 
mas ao contrário da conversa de Stephen com Sciama ele não expressa nenhuma palavra. Aos 40 minutos do filme (sequência 5), Stephen foi novamente representado como mantenedor do discurso científico durante um almoço. Durante a refeição, Hawking, Penrose, Sciama e sua esposa, conversavam especialmente sobre o tempo, intercalando momentos de descontração. A sequência é acompanhada por uma música erudita, que é silenciada no momento em que Hawking expressou o problema da Teoria do Estado Estacionário, cuja negação fora essencial para o desenvolvimento de sua tese. A elaboração do questionamento ocorre inesperadamente e indica o equívoco da teoria que explicava o funcionamento do universo defendido por Hoyle.

Aos 43 minutos (sequência 6), Stephen foi retratado investigando o trabalho de Hoyle, a fim de encontrar erros que pudessem fundamentar a sua crítica, processo esse que aparenta ter durado apenas uma noite. Representações como essa dão a entender que cientistas são gênios que, assim como o mito de Isaac Newton e a maçã, podem elaborar diversas teorias prontamente e com o mínimo de esforços. A representação de gênio foi reforçada durante o almoço retratado na sequência 5, no qual Penrose fez uma referência à genialidade de Mozart: "Mozart foi dormir e acordou com uma sinfonia inteira na cabeça sem ter a menor ideia de como ela chegou lá”. Entendemos que o filme pretende produzir o sentido de genialidade atribuído à Hawking de modo análogo ao mito de Mozart.

Após encontrar os equívocos da Teoria do Estado Estacionário, Stephen participou de uma palestra na Royal Society, onde o artigo de Hoyle fora apresentado (sequência 7). Após a apresentação, Hawking fez uma crítica contundente alegando que a matemática do trabalho de Hoyle estava errada, o que implicava na nulidade da Teoria do Estado Estacionário. De acordo com o filme, o diálogo ocorreu do seguinte modo: "[Stephen] Seus cálculos estão errados. O campo avançado diverge. [Hoyle] O campo avançado não diverge. [Stephen] Não, eu temo que sim. Está tudo errado. [Hoyle] Você gostaria de nos dizer como você sabe disso, rapaz? [Stephen] Eu calculei”. Pode-se notar que apesar de fundamentada, a crítica foi realizada sem a apresentação dos cálculos, evidenciando que o cientista acreditava ter a verdade ao seu lado. Essa interpretação é fortalecida pela produção da cena, que foi composta pelo arranjo de três planos. No primeiro, Hawking foi filmado de costas no lugar mais elevado do anfiteatro enquanto Hoyle estava no centro do tablado em posição mais baixa. O plano foi composto ainda por diversos outros pesquisadores que assistiam à palestra, embora Hawking fosse o único a interagir e o único espectador que estava em pé durante a sequência. 
Figura 2. Questionamento de Hawking a Hoyle

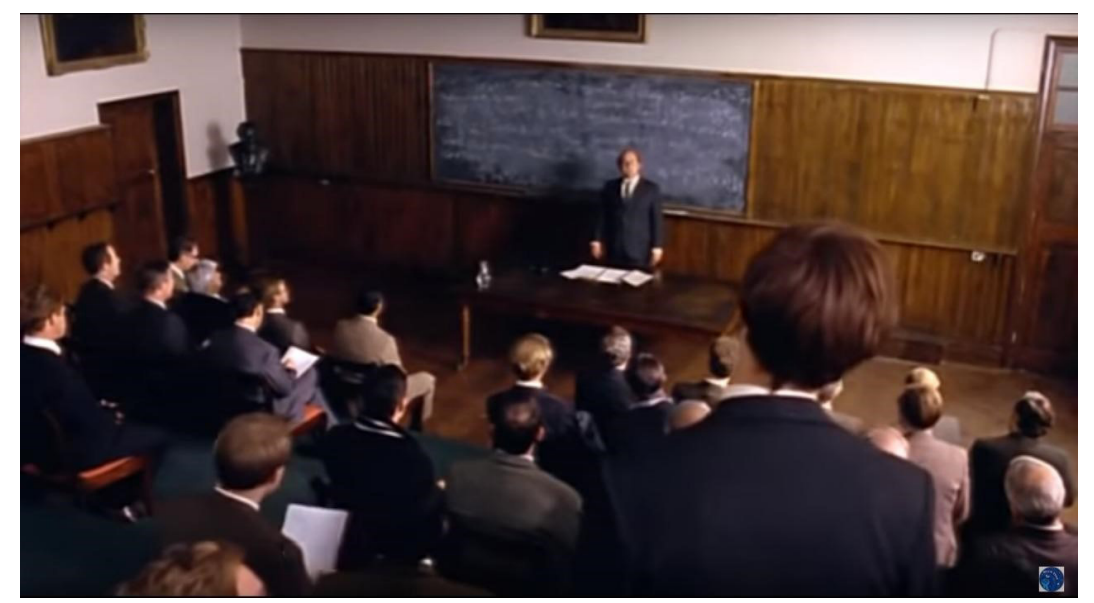

Os planos seguintes foram compostos pelo close de Hoyle e de Hawking, possibilitando uma interpretação de uma discussão entre pares, com uma controvérsia entre vozes equipolentes, como vemos a seguir:

Figura 3. Resposta de Hoyle ao questionamento de Hawking

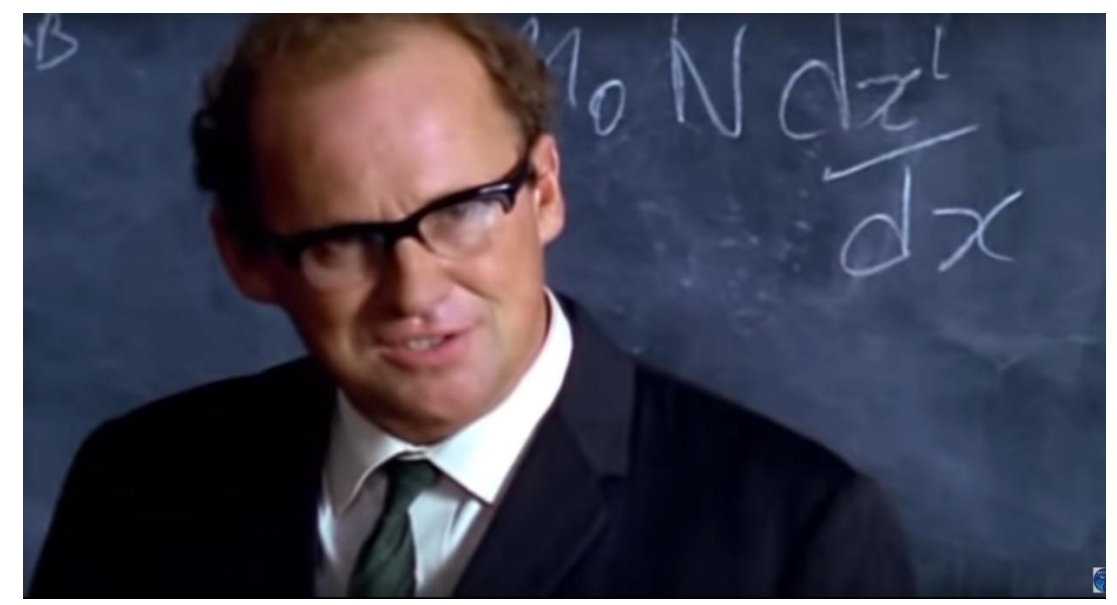

Figura 4. Réplica de Hawking à Hoyle

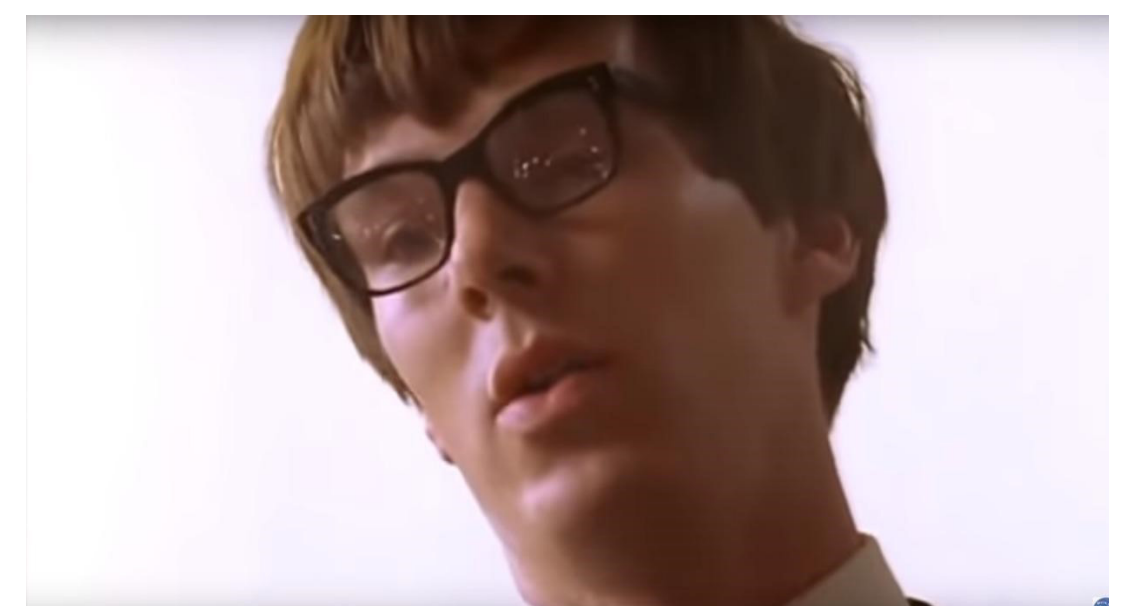


A Figura 2 apresenta um efeito em que a imagem de Hawking parece maior do que a imagem de Hoyle e encerra o silêncio imposto por Hoyle à Stephen na sequência (4), exposta entre os 38 e 39 minutos do filme. O próprio fato de Hawking ter se levantado pode produzir sentidos, uma vez que a cena se deu após uma sequência demarcada pelos seguintes momentos: 1 . o silenciamento de Stephen, 2. a elaboração do problema, 3. a revisão do trabalho de Hoyle e 4. o confronto das teorias. Esses momentos fortalecem a representação de genialidade, especialmente porque o desenvolvimento científico foi apresentado de modo linear, inesperado e sem a representação de um trabalho intenso de Stephen.

Ferguson (2011), em seu livro sobre a biografia de Hawking, escreveu sobre esse encontro. A sala de Stephen no departamento de matemática aplicada e física teórica era lado a lado da sala de Jayant Narlikar, aluno e coautor do trabalho de Hoyle sobre o Estado Estacionário. Os dois físicos se conheceram num curso de verão antes de Hawking se mudar para a Universidade de Cambridge e conversavam sobre o trabalho que estava sendo desenvolvido. Embora Hawking tenha feito os cálculos sozinho, isto não foi feito em apenas uma noite, como o filme mostra. A palestra aconteceu tal como foi retratada no filme, inclusive o "Eu calculei" dito por Hawking como principal argumento para contradizer Hoyle. De acordo com Ferguson (2011):

Sem saber que Hawking e Narlikar haviam discutido os resultados muitas vezes e que Hawking havia feito seus próprios cálculos, Hoyle e a plateia supuseram que esse estudante desconhecido havia 'resolvido' em sua cabeça ali mesmo na palestra. A plateia ficou impressionada; Hoyle estava furioso. Surpreendentemente, Hawking parece não ter perdido a amizade de Narlikar. De qualquer forma, sua reputação de brilhantismo e ousadia havia começado, assim como seu interesse em cálculos e especulações relacionados ao universo em expansão (p. 58, tradução livre ${ }^{7}$ ).

A comparação da sequência com a história apresentada por Ferguson nos indica a equivalência da representação e da história quando focado no questionamento da teoria apresentada, ao mesmo tempo que sugere que houve o apagamento de contextos relevantes que conduziram Stephen em seu trabalho, como a sua interação com Narlikar. Ainda que o filme tenha mostrado um sujeito entregando o trabalho de Hoyle para Hawking, esse personagem sequer foi nomeado, quão menos indicado que havia uma relação de amizade e interação na pesquisa entre ele e Hawking.

Aos 63 minutos (sequência 8), uma nova representação de Hawking foi produzida. Durante uma noite em um bar de Jazz, o cientista apresentou um comportamento inadequado, composto por arrogância e excentricidade, seguido por um ato de ruptura

7 No original: Unaware that Hawking and Narlikar had discussed the results many times and that Hawking had done calculations of his own, Hoyle and the audience assumed that this unknown research student had 'worked it out' in his head right there at the lecture. The audience was impressed; Hoyle was infuriated. Surprisingly, Hawking seems not to have lost the friendship of Narlikar. In any case, his reputation for brilliance and brashness had begun, and so had his interest in calculations and speculation having to do with the expanding universe 
na narrativa. A representação ocorreu quando Stephen e Jane estavam sozinhos em uma mesa vendo as demais pessoas dançarem, sem que um contexto anterior explicasse o assunto, de modo que a conversa apareceu isolada da narrativa do filme:

“[Stephen] A luz azul está ressaltando a fluorescência que tem no sabão em pó. Por isso as camisas estão luminosas. [Jane] É muito estranho. [Stephen] Os vestidos são novos. Ainda não foram lavados, por isso não estão fluorescentes. Está vendo só? O grande cientista. Posso te dizer tudo sobre como uma roupa lavada reage à luz azul. Uma das grandes questões da nossa espécie, como fazer sua roupa reagir à luz azul. Você quer dançar? [Nesse momento Stephen sai da mesa em direção à pista de dança sem esperar a resposta de Jane]”.

A fala de Hawking mesclava ironia e sarcasmo para menosprezar conceitos científicos que diferiam daqueles que ele considerava importantes para um grande cientista. Essa representação se aproxima da imagem de louco e excêntrico, que é muito comum, tal como aparece em diversos filmes e seriados televisivos com personagens cientistas como Sheldon Cooper, em The Big Bang Theory; Doutor Brown, da saga De volta para o futuro; Rick, da série de animação Rick and Morty, entre outros. Esse tipo de comportamento não foi representado em outras sequências do filme, contudo ele também pode ser entendido como decorrente do momento pessoal de Stephen. Ao analisar o contexto de seu ato, notamos que a sequência aparece logo após o cientista ser informado sobre o diagnóstico e a irreversibilidade de sua doença. Portanto, o comportamento se deu quando Stephen estava passando por um momento de estresse tanto pela pressão envolvendo o desenvolvimento do doutorado quanto pelo diagnóstico informado.

O desfecho do filme ocorre a partir dos 70 minutos, quando Stephen estava voltando de Londres para Cambridge, após uma conversa com Penrose (sequência 9). Dentro do trem, ele se sentou em frente a uma senhora que começou o diálogo sobre a percepção de movimento considerando o movimento do trem ao lado no sentido contrário. Ao observar o movimento do outro trem, a senhora falou: "Pensei que já estávamos partindo. [Stephen] Eu também. [Senhora] Mas não é o nosso trem. [Stephen] Não, é o deles". Em seguida, ela continuou o diálogo falando sobre a plataforma em que estava o trem em que embarcaram, conhecida como Plataforma de Cambridge, e que coisas estranhas acontecem nela. Quando o mecanismo engatilhou e o trem produziu um leve solavanco para trás, Hawking começou a perceber que a sua tese deveria se basear na reversão do tempo. Em seguida, Stephen saiu do trem e correu chamando por Penrose, que o levara até lá. Stephen explicou sua formulação, defendendo o uso da proposta de Penrose, que explicava a singularidade em estrelas em colapso para entender o início do Universo, fato que corroboraria a Teoria do Big Bang. Seu momento de "Eureka"8 foi substituído por um momento "Bang", expressão utilizada por Stephen ao idealizar

8 Expressão utilizada pelo cientista Arquimedes de Siracusa (287 a.C.-212 a.C.) ao descobrir/formular o princípio de Arquimedes. 
a sua teoria. Essas representações também se assemelham ao mito de Arquimedes ao solucionar um problema proposto pelo rei de Siracusa, o que nos permite englobá-las numa mesma representação de gênios.

De acordo com o livro de White e Gribbin (2002), a ideia de Hawking sobre o início do universo não aconteceu dessa maneira. Os autores alegam que durante as várias idas ao King's College, onde Penrose estava dando suas palestras, Hawking, Sciama, seu orientador, e outros alunos discutiam sobre a matemática envolvida no curso. Um dia, durante o caminho de volta para Cambridge, estavam num compartimento de segunda classe do trem falando sobre a palestra, quando Stephen se perdeu em pensamentos olhando para os campos envoltos na escuridão. De repente teve uma ideia, a qual compartilhou com seu orientador: "Me pergunto o que aconteceria se aplicássemos a teoria da singularidade do Roger ao Universo inteiro". Chegando a Cambridge, Hawking se dedicou a essa ideia e trabalhou como nunca antes. De acordo com o físico: "Eu... comecei a trabalhar duro pela primeira vez na minha vida. E para minha surpresa, eu descobri que eu gostava. Talvez não seja justo chamar isso de trabalho."9 (Hawking, citado em White e Gribbin, 2002).

Outro elemento que fortalece a representação de gênio é a encenação do trabalho solitário do cientista, pois todas as formulações teóricas ocorreram sem a participação direta de outros pesquisadores. Ainda que a sequência tenha sido representada com a participação de Penrose, este não teve uma participação decisiva no diálogo, figurando como mero ouvinte a quem Stephen explicava sua teoria. Durante a produção de sua tese de doutorado, Hawking trabalhou sozinho e mostrou o trabalho a seu orientador apenas depois de concluído. Em uma conversa entre Stephen, Sciama e Penrose, Sciama alegou: "Os três primeiros capítulos, nada de especial". Contudo, ao falar sobre o quarto capítulo, Penrose o interrompeu dizendo "Mozart", retomando a ideia de genialidade apresentada na sequência que encenava um almoço entre os três cientistas.

Ressaltamos ainda que todos os momentos criativos de Hawking foram acompanhados sonoplasticamente por músicas eruditas, fato que também produz sentidos, especialmente quando associados à crença popular de que o gosto por música erudita está ligado à inteligência. Tal crença, também é conhecida como efeito Mozart, se fundamenta na ideia "de que a exposição à música clássica (especialmente a música de Mozart) melhora a inteligência” (Bangerter \& Heath, 2004, p. 606). Após investigar extensivamente a origem e a evolução do efeito Mozart, Bangerter e Heath (2004) o classificam como uma lenda científica. Eles ressaltam que "o efeito Mozart é onipresente na cultura americana, onde a mídia e vários grupos de interesse rapidamente viram nele uma nova e fácil técnica para aprimorar a inteligência” (Bangerter \& Heath, 2004, p. 609), fato que, de acordo com os autores, também pode ser observado em outros países. Baseado nisso, entendemos que a música erudita é um efeito utilizado pelos diretores para evidenciar a inteligência e a genialidade de Stephen, uma vez que essa associação é comum em diversos países.

9 No original: "I ... started working hard for the first time in my life. To my surprise, I found I liked it. Maybe it is not really fair to call it work." 


\section{A teoria de tudo}

O filme "A teoria de tudo"10, diferentemente de "A história de Stephen Hawking", retrata um período mais longo da vida do cosmólogo - desde sua passagem pela Universidade de Cambridge até a rejeição do título de cavaleiro concedido pela rainha Elizabeth. Outra diferença marcante é a fonte de informações - enquanto o primeiro filme procura tecer uma narrativa baseada em registros documentais, este se baseou na percepção da primeira esposa de Stephen. O longa-metragem fez muito sucesso, sendo indicado ao Oscar nas categorias melhor ator, melhor atriz, melhor filme, melhor trilha sonora original e melhor roteiro adaptado, sagrando Eddie Redmayne (Stephen Hawking) com o prêmio de melhor ator, em 2015.

"A teoria de tudo" também conta com três fios narrativos, que por vezes se entrelaçam. O primeiro e principal fio narrativo retrata a luta de Stephen contra a doença Esclerose Lateral Amiotrófica (ELA). Por ser uma obra que apresenta um período maior da vida do cientista, há a representação das diversas fases do desenvolvimento da ELA e de como Hawking conseguiu superar as dificuldades impostas pelas limitações físicas. O segundo fio narrativo acompanha as principais realizações científicas de Stephen, incluindo algumas das premiações recebidas. A terceira linha narrativa aborda as relações amorosas de Hawking, especialmente com sua primeira esposa, Jane Wilde. As três linhas narrativas, às vezes, se cruzam indicando relações entre a carreira, a evolução da doença e a vida amorosa do cientista. Como o objetivo deste trabalho é analisar a representação do cientista, as análises a seguir estão baseadas, sobretudo, na narrativa sobre a carreira de Hawking.

Da mesma forma que no filme anterior, organizamos as cenas/sequências na Figura 5 contendo o tempo em que elas iniciam e uma breve descrição das mesmas.

Figura 5. Cenas e Sequências do filme "A Teoria de Tudo" (continua)

\begin{tabular}{|c|c|l|}
\hline $\begin{array}{c}\text { Cena/ } \\
\text { Sequência }\end{array}$ & Duração & Descrição \\
\hline 1 & $\begin{array}{c}2: 11 \text { - } \\
4: 20\end{array}$ & $\begin{array}{l}\text { Festa na Universidade. Durante uma festa estudantil em Cambridge, Jane, } \\
\text { conhece Hawking, momento que ambos trocam ideias. }\end{array}$ \\
\hline 2 & $\begin{array}{c}7: 59- \\
12: 26\end{array}$ & $\begin{array}{l}\text { Dez perguntas impossíveis. Stephen realiza um trabalho considerado } \\
\text { "impossível" em pouco tempo. }\end{array}$ \\
\hline 3 & $\begin{array}{c}15: 50- \\
17: 10\end{array}$ & $\begin{array}{l}\text { Baile de Maio. Stephen explica o porquê das camisas e gravatas dos homens } \\
\text { reagirem à luz negra. }\end{array}$ \\
\hline 4 & $\begin{array}{c}20: 32- \\
22: 06\end{array}$ & $\begin{array}{l}\text { Ideia sobre a pesquisa. O cosmólogo tem uma ideia sobre a sua pesquisa } \\
\text { ao observar uma imagem formada pelo leite que havia posto em seu café. }\end{array}$ \\
\hline
\end{tabular}

10 Os direitos autorais não foram cedidos para a publicação deste trabalho. Por isso durante as análises não são apresentadas imagens. 
Figura 5. Cenas e Sequências do filme "A Teoria de Tudo" (continuação)

\begin{tabular}{|c|c|c|}
\hline $\begin{array}{l}\text { Cena/ } \\
\text { Sequência }\end{array}$ & Duração & Descrição \\
\hline 5 & $\begin{array}{l}22: 57- \\
24: 21\end{array}$ & Formulação da teoria. Stephen desenvolve os cálculos para sua teoria. \\
\hline 6 & $\begin{array}{l}27: 35- \\
30: 13\end{array}$ & $\begin{array}{l}\text { Recusa de ajuda. Hawking, motivado pela situação na qual a doença o } \\
\text { colocava, afasta seus amigos. }\end{array}$ \\
\hline 7 & $\begin{array}{l}39: 40- \\
42: 24\end{array}$ & Defesa de doutorado. Stephen defende a sua tese. \\
\hline 8 & $\begin{array}{l}42: 24- \\
44: 52\end{array}$ & $\begin{array}{l}\text { Comemoração da defesa. Stephen, junto com seus amigos confraternizam } \\
\text { após a defesa da sua tese. }\end{array}$ \\
\hline 9 & $\begin{array}{l}48: 11- \\
49: 28\end{array}$ & $\begin{array}{l}\text { Ideia sobre a Radiação Hawking. Após tentar vestir um suéter sozinho, } \\
\text { Stephen tem uma ideia sobre um novo tipo de radiação. }\end{array}$ \\
\hline 10 & $\begin{array}{l}49: 28- \\
53: 03\end{array}$ & $\begin{array}{l}\text { Apresentação da sua nova teoria. Hawking apresenta sua teoria para um } \\
\text { grupo de pesquisadores na Royal Society. }\end{array}$ \\
\hline 11 & $\begin{array}{l}100: 28- \\
105: 07\end{array}$ & $\begin{array}{l}\text { Discussão entre Jane e Stephen. O casal discute após Hawking avisar que } \\
\text { irá para os EUA receber mais um prêmio. }\end{array}$ \\
\hline
\end{tabular}

O filme começa com uma festa da Universidade de Cambridge, a primeira fala da amiga de Jane Wilde, cujo nome não foi mencionado, demonstrou a percepção de uma representação comum dos cientistas, a de que são chatos e entediantes: "Eu conheço todos aqui... Brilhante! Minha nossa! Cientistas. Não precisamos ficar muito tempo, parece chato. Maçantes". Stephen, entretanto, foi representado rodeado de amigos, sociável, o que rompe com uma representação tradicional dos cientistas.

Aos 8 minutos (sequência 2), o seu colega de quarto Brian lembrou ao protagonista, estudante de doutorado recém-chegado à Universidade, que ele deveria realizar um exercício que continha "dez perguntas impossíveis". Em poucas horas, Stephen respondeu a nove delas, enquanto seus colegas de turma não responderam a uma sequer em uma semana. A resolução se deu em uma cena em que Stephen tinha acabado de acordar, ainda vestia o pijama e utilizava um panfleto com os horários dos trens para escrever as soluções porque não tinha encontrado um material adequado em sua mesa bagunçada. Essa representação foi o primeiro sinal de que Hawking seria apresentado como um gênio. Ressaltamos que a cena em que Stephen soluciona os problemas foi acompanhada sonoplasticamente por uma música erudita, efeito sonoro que foi replicado nos momentos que representam o desenvolvimento científico de Hawking. Assim como no filme "A história de Stephen Hawking", há a intenção dos produtores de "A teoria de tudo" de associar a música erudita à inteligência, tal como a lenda científica sobre o efeito Mozart.

Aos 15 minutos (sequência 3), Stephen levou Jane para o Baile de Maio, uma festa tradicional da Universidade de Cambridge. Durante a sequência do baile em que 
Stephen se negou a dançar, o físico explicou para Jane o motivo das camisas e gravatas dos homens brilharem mais do que os vestidos das mulheres quando expostos à luz negra. Em seguida falou também sobre como seria observar o universo sob a perspectiva da luz ultravioleta. Esse é um comportamento que corrobora o estereótipo de que cientistas buscam refúgio na ciência para manter um diálogo, ou seja, o filme faz uma representação de que Stephen é mantenedor do discurso científico.

Quando o filme volta a abordar a carreira do cosmólogo - aos 20 minutos (sequência 4) - , ele estava numa palestra do matemático Robert Penrose, que falava sobre a primeira Teoria de Buracos Negros. Logo ao fim dessa palestra, o físico descobriu o seu tema de doutorado. $\mathrm{O}$ momento de decisão sobre o tema da pesquisa ocorreu quando Stephen estava no trem voltando para Cambridge. Sentado em uma cadeira em frente a uma mesa com uma xícara de café ele falou: "[Hawking] Me pergunto o que aconteceria se aplicássemos a teoria de Penrose a todo universo". Dentre os elementos significantes da cena, Stephen colocou leite na xícara com café vagarosamente formando um círculo, com o fundo preto e o arco branco, imagem que retomava o desenho feito por Penrose com giz branco no quadro-negro durante a palestra (sequência anterior).

Este acontecimento é retratado em ambos os filmes, de maneiras diferentes. Como já dito, Hawking não estava sozinho durante esse momento de insight. Embora em "A teoria de tudo" o momento tenha sido mais fiel às biografias, a sequência não apresenta as pessoas que o acompanhavam, o que favorece o estereótipo de gênio, uma vez que o físico não discute a sua ideia com ninguém.

Na sequência seguinte (sequência 5), Hawking explicou sua ideia a Jane, em um momento composto tanto pelo desenvolvimento científico do protagonista quanto pelos traços de romantismo entre os dois, sequência que indica o entrelaçamento entre as narrativas do filme. Em seguida, Stephen apresentou sua ideia ao seu orientador, momento em que é sugerido a ele desenvolver os fundamentos matemáticos da sua hipótese: de que o universo surgiu da explosão de um buraco negro. Tal procedimento é realizado em apenas uma sequência, em que os planos são sobrepostos rapidamente, produzindo o efeito de rapidez e de temporalidade curta. A sequência que representa o desenvolvimento científico de Stephen foi acompanhada por música erudita e foi rompida pela queda do cientista, o que o leva ao médico que diagnosticou sua doença. A encenação do trabalho para o desenvolvimento matemático que contribuiria com sua hipótese, ainda que contasse com poucos planos (cena) em que Stephen apagava a equação que escreveu, indica uma atividade que foi realizada com facilidade por um cientista genial.

Após descobrir a sua doença, aos 27 minutos (sequência 6), Stephen é representado com comportamentos antissociais na tentativa de afastar as pessoas que o querem perto, sequência que reforça a imagem do cientista solitário, que não precisa de ajuda. Ainda que o comportamento de Hawking se enquadre em uma representação comum do cientista, sua ação é compreensível, já que por um lado pode ser interpretada como altruísta, pois não queria que as pessoas que amava sofressem após a sua especulada morte, e por outro lado, egoísta, pois o único desejo de Stephen era terminar seu trabalho de doutorado, 
independentemente do desejo de outras pessoas apoiarem ou quererem compartilhar o tempo com ele. Assim, o isolamento não ocorreu por conta de um sentimento de superioridade ou por uma incapacidade de manter relações sociais adequadas.

No desenrolar da trama, Stephen se casou com Jane e defendeu seu doutorado. Durante a defesa, aos 39 minutos sequência 7), Sciama perguntou a Hawking o que viria a seguir, ao que ele respondeu: "[Hawking] Provar. Provar, com uma única equação, que o tempo teve um início. Isso não seria bom professor? Uma equação simples, mas uma equação engenhosa para explicar tudo". A cena retrata a imagem de que mesmo após conquistas os cientistas continuam ambiciosos e desejam cada vez mais e também a determinação de Hawking em continuar o trabalho independentemente das dificuldades que lhe eram impostas pela doença.

Durante a comemoração da defesa (sequência 8), seus amigos falavam sobre como ele era preguiçoso e que não se dedicava o quanto deveria: "[Amigo 1] É incrível ele ser a primeira pessoa a concluir o doutorado considerando o pouco trabalho que tem feito. [Amigo 2] Trabalho era a pior palavra para Stephen. Em Oxford, principalmente, ele tinha a média de uma hora, uma hora diária, em média. E aqui está o homem estimado. Incríveis níveis de preguiça". Essa representação reforça a ideia de que ele era um gênio que não precisava se esforçar para o desenvolvimento do trabalho científico.

Mesmo com o avanço da sua doença, Stephen nunca desistiu de lutar e de se dedicar às suas pesquisas. Sua representação no filme é frequentemente relacionada a de um gênio. Aos 48 minutos (sequência 9), Stephen, já num estágio um pouco mais avançado da doença, tentava vestir uma blusa sozinho e ela se prendeu em sua cabeça possibilitando que ele visse a sua lareira entre os fios de lã da blusa. A partir da visão do fogo, ele elaborou a ideia de que os buracos negros emitem uma radiação decorrente de fenômenos quânticos: a radiação Hawking.

Logo após, durante a apresentação da sua nova teoria (sequência 10), Stephen foi provocado por um pesquisador, cujo nome não foi citado, que afirmou que a sua teoria era uma bobagem sem sentido. Hawking se manteve firme ironizando a afirmação do colega, perguntando se havia falado alguma besteira, enquanto esse saía do auditório. Em seguida, Isaak Khalatnikov, um dos grandes nomes no estudo do universo quente e dos buracos negros, reconheceu a teoria de Stephen como algo inovador. "[Khalatnikov] Eu vim aqui hoje esperando ouvir muita bobagem. Vou para casa decepcionado. O pequeno aqui, conseguiu". Essa fala do professor evidencia as disputas e contradições presentes na produção do conhecimento científico.

De acordo com Ferguson (2011), o processo da proposição da Radiação Hawking ocorreu em meio a disputas científicas e trabalho colaborativo. A autora alega que um pós-graduando em física, chamado Jacob Bekenstein, havia questionado uma metáfora de Hawking de que a área do evento de horizontes de um buraco negro é parecida com entropia. Para esse jovem físico, a área não era parecida, era entropia. Em 1972 e 1973, irritado com o que poderia ser um uso indevido da sua teoria, Hawking se juntou a James Bardeen e Brandon Carter, dois colegas físicos, e juntos formularam as quatro leis da mecânica dos buracos negros. 
Ainda de acordo com Ferguson (2011), em 1973, Hawking resolveu olhar para os buracos negros pelos olhos da mecânica quântica. Em agosto desse ano, o físico se dirigiu a Moscou e se encontrou com Yakov Borisovich Zel'dovich e seu aluno de pósgraduação Alexander Starobinsky. Os físicos russos estavam desenvolvendo uma teoria de que os buracos negros poderiam emitir partículas, o que faria com que a sua rotação diminuísse até parar completamente e deixasse de emitir tais partículas. Hawking, no entanto, não ficou contente com os cálculos feitos e resolveu fazer os cálculos ele mesmo. Feito isso, encontrou uma surpresa: mesmo os buracos negros não rotativos emitem partículas numa taxa estável.

Após revisar várias vezes os cálculos a fim de encontrar erros, Hawking chegou à conclusão de que Bekenstein estava correto. Não é possível diminuir a entropia do universo apenas "jogando" matéria contendo entropia em buracos negros como se fossem grandes latas de lixo. A partir disso, Hawking então descreve como a interação entre pares de partículas subatômicas tais como férmions e antimatéria, fótons e grávitons, daria espaço para que uma dessas partículas escapasse do horizonte de eventos. Essas partículas dariam então origem à teoria da radiação Hawking (Ferguson, 2011).

A comparação entre a história e a representação de Hawking no filme nos indica formas particulares da produção do estereótipo. Nesse caso, há o apagamento dos contextos sociais e da própria história, especialmente das etapas de formulação e desenvolvimento das ideias. Esse apagamento, por desconsiderar a ação de outros sujeitos, corrobora o fortalecimento do estereótipo de gênio. Nesse sentido, a representação do filme, além de contribuir para uma interpretação inadequada da figura do cientista conduz os espectadores a uma visão equivocada da natureza da ciência.

Nas sequências seguintes, o diretor decidiu focar na luta do protagonista contra a sua doença, explorando o lado familiar e o apoio dos seus amigos. Pouco foi abordado sobre sua rotina de trabalho, mas os seus feitos foram exaltados, como por exemplo o lançamento do seu primeiro livro, Uma breve história do tempo.

O desfecho do filme ocorre aos 100 minutos (sequência 11), quando Stephen contou a Jane, com um sorriso debochado, que iria para os Estados Unidos para receber mais um prêmio. Ao utilizar essa expressão, mais um prêmio, ele se mostrou imponente e vaidoso, reforçando a representação de que cientistas bem-sucedidos são o centro do universo e que devem mesmo ser reconhecidos pela sua grandeza. A imponência e vaidade do cientista foi ofuscada, quando evidenciamos o contexto da sequência, pois o filme relata que o relacionamento de Stephen e Jane estava sucumbindo aos poucos. A atitude dele se deu quando tentava aliviar um momento de tensão entre o casal.

\section{Considerações Finais}

Este artigo teve o objetivo de analisar dois filmes biográficos de Stephen Hawking: "A história de Stephen Hawking" e "A teoria de tudo", produzidos pela BBC e pela Universal Studios, respectivamente, com o intuito de identificar as representações do cientista presente nas obras. A análise indicou que ambos os filmes representam 
Stephen Hawking como um cientista genial, que não necessita fazer muitos esforços para conseguir os seus feitos, sendo essa, inclusive, a representação mais marcante e evidente das obras. Nos dois filmes, o cosmólogo é encenado realizando pesquisas ou correções complexas num período muito curto de tempo e com poucas interações com os pares, o que fortalece essa imagem.

Para organizar as conclusões de maneira a dar mais consistência aos argumentos, compilamos todos os estereótipos encontrados durante a análise, indicando as cenas de cada filme nas quais Stephen Hawking foi relacionado a eles.

Figura 6. Relação entre estereótipos e cenas/sequências dos filmes

\begin{tabular}{|c|c|c|}
\hline Estereótipo & "A história de Stephen Hawking" & "A Teoria de Tudo" \\
\hline $\begin{array}{l}\text { Isolamento/ } \\
\text { Solitário }\end{array}$ & $\begin{array}{l}\text { a. Festa de aniversário. } \\
\text { b. Insight na estação Cambridge. } \\
\text { c. Diluído ao longo do filme. }\end{array}$ & a. Recusa de ajuda. \\
\hline Excêntrico & $\begin{array}{l}\text { a. Festa de aniversário. } \\
\text { b. Confraternização num bar de Jazz. }\end{array}$ & Não foi identificado nesse filme. \\
\hline $\begin{array}{l}\text { Mantenedor } \\
\text { do discurso } \\
\text { científico }\end{array}$ & $\begin{array}{l}\text { a. Festa de aniversário. } \\
\text { b. Consulta médica. } \\
\text { c. Encontro com amigos no bar. } \\
\text { d. Almoço com Stephen, Penrose, Sciama e sua } \\
\text { esposa. }\end{array}$ & $\begin{array}{l}\text { a. Baile de Maio. } \\
\text { b. Formulação da teoria. }\end{array}$ \\
\hline Arrogante & $\begin{array}{l}\text { a. Debate com Hoyle nos corredores. } \\
\text { b. Contestação do trabalho de Hoyle. } \\
\text { c. Confraternização num bar de Jazz. }\end{array}$ & Não foi identificado nesse filme. \\
\hline Irônico & a. Entrevista de Hoyle a um canal de televisão. & a. Apresentação da sua nova teoria. \\
\hline Gênio & $\begin{array}{l}\text { a. Almoço com Stephen, Penrose, Sciama e sua } \\
\text { esposa. } \\
\text { b. Investigação do trabalho de Hoyle. } \\
\text { c. Contestação do trabalho de Hoyle. } \\
\text { d. Insight na estação Cambridge. }\end{array}$ & $\begin{array}{l}\text { a. Dez perguntas impossíveis. } \\
\text { b. Ideia sobre a pesquisa. } \\
\text { c. Formulação da teoria. } \\
\text { d. Comemoração da defesa. } \\
\text { e. Ideia sobre a Radiação Hawking. }\end{array}$ \\
\hline Louco & a. Confraternização num bar de Jazz. & Não foi identificado nesse filme. \\
\hline $\begin{array}{l}\text { Entediante e } \\
\text { chato }\end{array}$ & Não foi identificado nesse filme. & a. Festa na Universidade. \\
\hline Ambicioso & Não foi identificado nesse filme. & a. Defesa de doutorado. \\
\hline $\begin{array}{l}\text { Imponente/ } \\
\text { Vaidoso }\end{array}$ & Não foi identificado nesse filme. & a. Discussão entre Jane e Stephen. \\
\hline
\end{tabular}


A Figura 6 representa a catalogação das cenas de ambos os filmes, de acordo com os estereótipos encontrados neles. Como é possível ver, em ambos os longas, o estereótipo de gênio foi o mais encontrado, seguido pelo estereótipo de mantenedor do discurso científico, fato que corrobora a interpretação de que ambos os filmes buscam representar a genialidade de Hawking. Não identificamos similaridade entre os filmes no que se refere a outros estereótipos, mesmo porque alguns aparecem apenas uma vez, o que impossibilita a definição de padrões.

Em “A história de Stephen Hawking”, o estereótipo de cientista solitário é reforçado, tendo sido encontrado em três sequências. Este é um ponto que indica a representação de Hawking como herói, visto que é representado como um gênio solitário, ou seja, não precisa de outras pessoas ajudando no desenvolvimento de seu trabalho. Já em "A teoria de tudo", a ampla representação do estereótipo gênio, associada à ausência de estereótipos negativos, como excêntrico, arrogante ou louco, também reforçam a representação do cientista como herói.

Quando apontamos a representação de gênio não queremos, de forma alguma, ofuscar o fato de Hawking ter sido um grande cientista do século XX. Ressaltamos que consideramos, desde o início, que essa representação está acompanhada do ofuscamento do trabalho necessário para o desenvolvimento de suas propostas. Portanto, a imagem de gênio está baseada em uma elaboração científica inesperada, repentina e abrupta. A triangulação com a história de Stephen nos indica que a produção desse estereótipo foi acompanhada do apagamento dos contextos históricos e sociais vivenciados por Hawking, de modo que o cientista foi representado no cinema como o único responsável por tais feitos, sem que fossem representados os outros sujeitos envolvidos, tal como indicado nas biografias consultadas.

A presença dessa representação pode ser, inclusive, um efeito fortalecido pelo gênero cinematográfico biografia. Os filmes biográficos têm como principal característica a representação dramática de algum sujeito real. Geralmente as biografias, no cinema, buscam a representação heroica do personagem que, no caso do cientista, pode estar relacionada à genialidade. Entendemos que essa consideração pode ser aprofundada em um estudo da representação de cientistas em biografias, fundamentados em Barca (2005) que defende que, a partir de 2000, o cientista é representado como herói.

Se analisarmos a duração das sequências dos dois filmes, podemos perceber como as sequências de "A história de Stephen Hawking" são substancialmente mais longas que de "A teoria de tudo". Tendo em vista que o primeiro foi feito se baseando em documentos históricos, enquanto o segundo foi baseado no livro de Jane Wilde, acreditamos que a produção hollywoodiana contribua mais para a construção do estereótipo de herói para Hawking. As cenas são curtas demonstrando que o cientista necessita de pouco tempo para realizar seus feitos, o que também implica que ele não erra, ou erra raramente, uma vez que completa suas tarefas em uma pequena cadeia de atividades. Outro ponto que corrobora essa conclusão é que não foram encontrados, em "A Teoria de Tudo", os estereótipos negativos: louco, excêntrico e arrogante. Essa omissão de traços de personalidade é outra maneira de construir a imagem de herói. 
Também foi possível identificar nas obras outras representações como antissocial, mantenedor do discurso científico, louco, excêntrico, ambicioso, arrogante, bemsucedido, imponente e vaidoso. Ao analisar os contextos sociais nos quais o personagem estava inserido e as sequências que o levaram a agir de tais maneiras, é possível entender os motivos para as ações classificadas nessas representações. Portanto, essas imagens, ainda que pareçam antagônicas, não desconstroem a representação heroica, embora apontem pequenas rupturas na narrativa para a produção do herói.

Considerar os contextos narrativos nas análises nos apontou que as representações não são unidades plenamente estáveis e coesas, mas que podem, sim, carregar contradições que são determinadas pela história do sujeito e pelos contextos sociais vivenciados, tal como apontado por Oliveira (2006).

A representação da comunidade científica, por sua vez, indicou aspectos como: área entediante, arrogância, trabalho coletivo, um trabalho contínuo (perseverante) e disputas durante a produção do conhecimento científico. Além disso, foi evidente em ambos os filmes a escassez da representação de mulheres cientistas, bem como de cientistas de outras origens étnicas (não caucasianos) ${ }^{11,12}$. Resultados que fortalecem as representações mais frequentes do cientista indicadas pela literatura (Flicker, 2003; Jackson,2011; Ramos \& Olschowsky, 2009; Weingart et al., 2003).

Acrescentamos a necessidade da incorporação de elementos não-verbais nas análises sobre as representações do cientista e da ciência no cinema. Reconhecemos a dificuldade de contemplar os diversos aspectos da produção cinematográfica, embora a análise da produção das cenas e sequências, bem como de sua associação a trechos da trilha sonora e texto, tenha indicado sentidos que corroboraram a classificação das ações do cientista em determinada representação. Evidentemente, não é possível fazer a análise de todos os elementos presentes na obra em um artigo científico, contudo considerar esses elementos para a análise abre novas possibilidades de interpretar as relações entre o cinema e a cultura científica.

As análises indicam que os filmes biográficos de Stephen Hawking se fundamentam na espetacularização de momentos da vida do cientista para ressaltar seus grandes feitos científicos ou mesmo os dramas pessoais vividos. Essa constatação, ao ser agregada às considerações de Dijck (2006) sobre os documentários científicos da televisão, indica que a representação do cientista no cinema não segue caminhos que tentam retratar fidedignamente a história do cientista e a história da ciência. Dijck (2006) ressalta que "o efeito pictórico e o modo narrativo especulativo podem se infiltrar e até dominar um programa de televisão, e mesmo assim os produtores optam por prestar uma homenagem cuidadosa às características realistas do gênero documentário"(p. 21) ${ }^{13}$. Essa mesma

11 Acreditamos que o diálogo sobre a representação da mulher cientista nos filmes seja muito importante, embora esse não tenha sido o foco deste trabalho. Em ambos os filmes a mulher é representada predominantemente em papéis secundários e fora do ambiente acadêmico.

12 Outro ponto que decidimos não abordar é a representação de cientistas não caucasianos. Em ambos os filmes essa representação é quase nula.

13 No original: "the pictorial effect and speculative narrative mode may infiltrate and even dominate a television programme, and yet producers choose to pay careful tribute to the realist features of the documentary genre" 
característica pode ser observada nos filmes "A história de Stephen Hawking" e "A teoria de tudo", que foram baseados, respectivamente, em documentos históricos e na biografia do cientista escrita por sua primeira esposa.

Os resultados de nossa análise também podem ser expandidos e repensados a partir das contribuições de Metz (2008) acerca dos documentários científicos. Metz (2010) alega que a combinação entre a realidade e a ficção estão presentes tanto na ficção científica quanto nos documentários científicos, fato esse que é problemático, uma vez que um rompimento dos vínculos entre o real e o conhecimento científico (significados) dificilmente será notado. O autor acrescenta que "esse desacoplamento do conhecimento científico e sua apresentação precisa sugere que a própria ciência é subjuntiva; isto é, não há realidade (científica) fora daquilo em que nós, como cultura, acreditamos"14 (Metz, 2008, p. 346). Tais contribuições são relevantes pois as biografias analisadas também podem ser entendidas como uma combinação entre a ficção e a realidade, cujas fronteiras não são bem demarcadas e por isso podem contribuir para uma interpretação equivocada da história da ciência e do personagem. Nas biografias, o distanciamento entre a representação e os acontecimentos reais da história pode favorecer uma representação que está mais baseada nos sentidos e valores adotados acerca dos sujeitos do que nos acontecimentos registrados historicamente, fato que, no nosso entendimento, pode deturpar a história do personagem e promover uma representação inadequada da CCT.

Portanto, os resultados indicaram que as biografias, assim como outros gêneros cinematográficos, também representam cientistas por meio de estereótipos e visões deturpadas da natureza do trabalho científico. Ressaltamos a necessidade de uma apreciação crítica dos filmes, que pode ser fomentada pela educação científica. Tal apreciação não deve ter o objeto de desqualificar ou mesmo menosprezar as ações e realizações do (a) cientista encenadas pelo cinema, mas sim contemplar outros aspectos, tais como: os contextos históricos e culturais do cientista; as condições para a produção científica; os valores atribuídos aos cientistas presentes no imaginário social; e também os interesses que permeiam as produções cinematográficas como a comercialização dos filmes.

A importância desta análise reside, ainda, em compreender os elementos que compõem a cultura científica (Polino \& Castelfranchi, 2012), incluindo aspectos aparentemente externos a ela, como a produção literária e cinematográfica que retratam sujeitos, temas científicos ou a produção do conhecimento científico. Tal compreensão contribui para uma interpretação mais adequada da cultura científica que é produzida por meio de diversas atividades, de interações sociais e do consumo de produções artísticas (cinema, literatura, artes plásticas, teatro etc.) e comunicativas (divulgação científica). Neste trabalho, reiteramos a influência do cinema como suporte para fomentar a percepção pública da ciência e o imaginário de elementos da cultura científica.

14 No original: "this uncoupling of scientific knowledge and its accurate presentation suggests that the science itself is subjunctive; that is, there is no (scientific) reality outside that which we as a culture believe" 


\section{Referências}

Alcântara, A. Y., \& Lima, G. S. (2018). Categorias para o uso educativo de filmes com elementos científicos e tecnológicos. Revista de Ensino de Ciências e Matemática, 9(1), 85-104. https://doi.org/10.26843/rencima.v10i1.1571

Almeida, S. A., \& Lima E. C. C. (2016). Cientistas em revista: Einstein, Darwin e Marie Curie na Ciência Hoje das Crianças. Ensaio: Pesquisa em Educação em Ciências, 18(2), 29-47. http://dx.doi.org/10.1590/1983-21172016180202

Bangerter, A., \& Heath, C. (2004). The Mozart effect: Tracking the evolution of a scientific legend. British Journal of Social Psychology, 43, 605-623 https://doi. org/10.1348/0144666042565353

Barbosa, L. C. A., \& Bazzo, W. A. (2013). O uso de documentários para o debate ciênciatecnologia-sociedade (CTS) em sala de aula. Ensaio: Pesquisa em Educação em Ciências, 15(3), 149-161. http://dx.doi.org/10.1590/1983-21172013150309

Barca, L. (2005). As múltiplas imagens do cientista no cinema. Comunicação \& Educação, X(1). http://www.revistas.usp.br/comueduc/article/viewFile/37507/40221

Candido, A. (1968). A personagem de Ficção (2a ed.). Editora Perspectiva.

Cazón, H. O. A., \& Oliveira, O. B. (2018). Relações com o saber na atividade de produção de documentário científico no ensino de biologia. Ensaio: Pesquisa em Educação em Ciências, 20, 1-21. https://doi.org/10.1590/1983-21172018200108

Cunha, M. B., \& Giordan, M. (2009). A Imagem da Ciência no Cinema. Química nova na escola, 31(1), 9-17. http://qnesc.sbq.org.br/online/qnesc31_1/03-QS-1508.pdf

Dijck, J. (2006). Picturizing science: The science documentary as multimedia spectacle. International Journal ofCultural Studies, 9(1). https://doi.org/10.1177/1367877906061162

Ferguson, K. (2011). Stephen Hawking, his life and work (1a ed.). Bantan Press.

Ferreira, J. D., \& Raboni, P. A. (2013). A ficção científica de Júlio Verne e o ensino de Física: uma análise de "Vinte Mil Léguas Submarinas". Caderno Brasileiro de Ensino de Física, 30, 84-103. https://doi.org/10.5007/2175-7941.2013v30n1p84

Flicker, E. (2003). Between brains and breasts-Women scientists in fiction film: On the marginalization and sexualization of scientific competence. Public Understanding of Science, 12(3), 307-318. https://doi.org/10.1177/0963662503123009

Gingras, Y. (2007). Henri Poincaré: The movie The Unintended Consequences of Scientific Commemorations. Isis, 98(2), 366-372. http://www.journals.uchicago.edu/ doi/abs/10.1086/521515

Gorp, B. V., Rommes, E., \& Emons, P. (2013). From the wizard to the doubter: Prototypes of scientists and engineers in fictions and non-fiction media aimed at Dutch children and teenagers. Public Understanding of Science, 23(6), 646-659. https://doi. org/10.1177/0963662512468566 
Grego K. 2013. 'The physics you buy in the supermarkets'. Writing science for the general public: the case of Stephen Hawking. In S. Kermas and T. Christiansen (eds), The Popularization of Specialized Discourse and Knowledge across Communities and Cultures. Edipuglia, 149-172

Hawking, S. W. (1975). Particle creation by black holes. Communications in Mathematical Physics, 43, 199-220. https://doi.org/10.1007/BF02345020

Hawking, S. W. (1993). Hawking on the Big Bang and Black Holes. World Scientific Pub. Haynes, R. D. (2016). Whatever happened to the 'mad, bad' scientist? Overturning the stereotype. Public Understanding of Science, 25(1), 31-44. https://doi. org/10.1177/0963662514535689

Jackson, J. K. (2011). Doomsday Ecology and Empathy for Nature: Women Scientists in 'B" Horror Movies. Science Communication, 33(4), 533-555. https://doi. org/10.1177/1075547011417893

Johnston, K. M. (2011). Science fiction film: a critical introduction. Berg

Long, M., \& Steinke, J. Applegate, B., Lapinski, M. K., Johnson, M. J., \& Ghosh, S. (2014). Portrayals of Male and Female Scientists in Television Programs Popular Among Middle School-Age Children, Science Communication, 32, 356-382. https://doi. org/10.1177/1075547009357779

Marcelo, F. A., \& Ripoll, D. (2016). A educação ambiental pelas lentes do cinema documentário. Ciência \& educação, 22(4), 1045-1062. http://dx.doi.org/10.1590/1516731320160040013

Marsh, J. (Diretor). (2014). A teoria de tudo [Filme]. Universal Studios.

Martin, P. (Diretor). (2004). A história de Stephen Hawking [Filme]. BBC Two.

McKie, R. (2007, 1 de Agosto). A brief history of Stephen Hawking. Cosmos. https:// cosmosmagazine.com/physics/a-brief-history-of-stephen-hawking

Metz, A. M. (2008). A Fantasy Made Real: The Evolution of the Subjunctive Documentary on U. S. Cable Science Channels. Television \& New Media, 9(4), 333-348. https://doi. org/10.1177/1527476408315117

Oliveira, B. J. (2006). Cinema e imaginário científico. História, Ciências, Saúde Manguinhos, 13, 133-50. http://dx.doi.org/10.1590/S0104-59702006000500009

Penafria, M. (2009). Análise de Filmes - conceitos e metodologia(s). In VI Congresso SOPCOM. http://www.bocc.ubi.pt/pag/bocc-penafria-analise.pdf

Perez, V. S. (2012). Pessoa com deficiência = pessoa incapaz? Um estudo acerca do estereótipo e do papel da pessoa com deficiência nas organizações. Cadernos EBAPE. $B R, 10(4)$, artigo 6, 883-893. http://dx.doi.org/10.1590/S1679-39512012000400007

Piassi, L. P. (2013). Clássicos do cinema nas aulas de ciências - A física em 2001: uma odisseia no espaço. Ciência e Educação, 19, 517-534. https://doi.org/10.1590/S151673132013000300003 
Piassi, L. P. C., \& Pietrocola, M. (2009). Ficção científica e ensino de ciências: para além do método de 'encontrar erros em filmes'. Educação e Pesquisa, 35, 525-540. https://doi. org/10.1590/S1517-97022009000300008

Polino, C., \& Castelfranchi, Y. (2012). Comunicación pública de la ciencia. Historia, prácticas y modelos. In E. Aibar, M. A.Quintanilla (Orgs.). Enciclopedia Ibero Americana de Filosofía: Ciencia, tecnología y sociedad, (Vol. 32) (pp. 351-378). Editorial Trotta.

Ramos, J., \& Olschowsky, J. (2009). As Representações Sociais de Cientistas em Filmes de Animação Infantil. XXXII Congresso Brasileiro de Ciências da Comunicação. http:// www.intercom.org.br/papers/nacionais/2009/resumos/R4-1225-1.pdf

Ramos, J. E. F., \& Piassi, L. P. C. (2017). O insólito e a física moderna: Interfaces didáticas do conto fantástico. Ciência \& Educação (online), 23, 163-180. http://dx.doi. org/10.1590/1516-731320170010010

Reznik, G., \& Massarani, L. (2019). Gender and science in animation: Analysis of the Anima Mundi Festival films. Journal of Science Communication, 18, p. A8. https://doi. org/10.22323/2.18020208

Roberts, A. (2016). The History of Science Fiction (2 ${ }^{\mathrm{a}}$ ed.). Palgrave Macmillan.

Rodrigues, A., \& Assmar, E. M. L. Jablonski, B. (1999). Psicologia social. Vozes.

Rose, D. (2017). Análise de imagens em movimento. In Bauer, M. W., Gaskell, G (org.). Pesquisa qualitativa com texto, imagem e som: Um manual prático. Editora Vozes Limitada.

Sadoul, G. (1963.) História do cinema mundial: Das origens a nossos dias (Volume 1). Martins.

Santos, W. J., \& Silva, I. P. (2017). Potencialidades do filme de ficção Avatar para a alfabetização científica dos sujeitos no contexto da educação básica. Amazônia: revista de educação em ciências e matemática, 13(28), 51-63. http://dx.doi.org/10.18542/ amazrecm.v13i28.5290

Scalf, G. A. M., \& Oliveira, M. M. (2015). Cine y ciencia: un análisis de los estereotipos presentes en la película infantil Frankenweenie, de Tim Burton. Alexandria, 8(2), 183197. http://dx.doi.org/10.5007/1982-5153.2015v8n2p183

Smith, M. K. (2001). 'What is non-formal education?', the encyclopedia of informal education. Infed.org. http://infed.org/mobi/what-is-non-formal-education/

Schmidt, B. B. (2014). Biografia: um gênero de fronteira entre a história e a literatura. In Rago, M., Gimenes, R. A. O. Narraropassado, repensar a história. Unicamp/IFCH,191-202.

Suppia, A. L. (2015). Em torno de cena e da sequência: problemas de categorização. Galáxia (São Paulo, Online), 30, 60-72.http://dx.doi.org/10.1590/1982-25542015220588

Weingart, P., Muhl, C., \& Pansegrau, P. (2003). Of power maniacs and unethical geniuses: science and scientists in fiction film. Public Understanding of Science, 12(3), 279-287. https://doi.org/10.1177/0963662503123006 
White, M., \& Gribbin, J. (2002). Stephen Hawking, a life in science (3a ed.). Joseph Henry Press.

Zanetic, J. (2006). Física e Arte: Uma ponte entre duas culturas. Pro-Posições, 17(1), 39-58. https://www.fe.unicamp.br/pf-fe/publicacao/2344/49_dossie_zaneticj.pdf

\author{
João Fernandes \\ Universidade de São Paulo \\ Instituto de Física \\ São Paulo, São Paulo, Brasil \\ joaof@if.usp.br \\ ${ }^{0}$ Guilherme da Silva Lima \\ Universidade Federal de Ouro Preto \\ Instituto de Ciências Exatas e Biológicas \\ Departamento de Física \\ Ouro Preto, Minas Gerais, Brasil \\ glima@ufop.edu.br \\ Orlando Aguiar Jr. \\ Universidade Federal de Minas Gerais \\ Faculdade de Educação \\ Departamento de Métodos e Técnicas de Ensino \\ Belo Horizonte, Minas Gerais, Brasil \\ oaguiar.ufmg@gmail.com
}

Editor Responsável

Cristiano Barbosa de Moura

Manifestação de Atenção às Boas Práticas Científicas e de Isenção de Interesse

Os autores declaram ter cuidado de aspectos éticos ao longo do desenvolvimento da pesquisa e não ter qualquer interesse concorrente ou relações pessoais que possam ter influenciado o trabalho relatado no texto. 